\title{
Senior house officer perspectives on the educational benefits of a local teaching programme at a specialist orthopaedic hospital
}

Steven Kyriacou ( $\nabla$ drstevenkyriacou@hotmail.co.uk)

University College London

Deborah Eastwood

Royal National Orthopaedic Hospital NHS Trust

\section{Research article}

Keywords: Post-graduate medical education, Orthopaedic, teaching programme

Posted Date: May 27th, 2020

DOI: https://doi.org/10.21203/rs.3.rs-29673/v1

License: (c) (i) This work is licensed under a Creative Commons Attribution 4.0 International License.

Read Full License 


\section{Abstract \\ Background:}

Delivering local teaching programmes equally relevant to all senior house officer (SHO) equivalent junior doctors within a tertiary level specialist hospital is challenging. This study aimed to establish the views of SHOs within a specialist orthopaedic hospital on the value of the current local teaching programme to their educational needs how it may potentially be improved?

\section{Methods:}

Data was collected via questionnaires of SHOs selected through a combination of convenience and purposive sampling. Responses underwent thematic analysis which utilised a hybrid model of a priori and emergent coding.

\section{Results:}

$12(50 \%)$ of SHOs within the hospital responded. Thematic analysis of completed questionnaires resulted in identification of 4 main themes: quality/utility of teaching, content of teaching, accessibility of teaching and non-educational benefits. Feedback received regarding the existing local teaching programme was largely positive. Opinions on the utility and content of the teaching programme were found to be the most varied.

\section{Conclusion:}

This study highlights the difficulties in delivering a teaching programme to a clinical learner group with diverse educational needs in a specialist hospital setting. Such issues may be minimised by learner survey to identify educational topics of equivalent utility to the majority of the learner group.

\section{Background}

The Royal National Orthopaedic Hospital is the largest specialist tertiary referral Orthopaedic hospital within the United Kingdom. The senior house officers (SHOs) within the Trust are from varied clinical backgrounds with differing levels of experience, career aspirations and training needs.

There is a weekly on-site 2-hour formal teaching programme intended solely for the SHOs within the Trust. This is aimed at providing generalised orthopaedic education catering to the learning needs of this group and is delivered by Trust Consultants and specialist registrar doctors. It is protected 'bleep free' educational time. Despite this, attendance at the teaching programme has previously been noted as being variable. 
The Committee of Postgraduate Medical Deans (COPMED) previously recommended a minimum set of standards for training SHOs, which included 'four hours of bleep free post-graduate education per week' (1). Despite these recommendations, previous studies have demonstrated this is not always provided to trainees. $47 \%$ of SHOs across a range of specialties and $69 \%$ of surgical trainees were found to not receive protected teaching in the study conducted by Cooke and Hurlock (1999) based on the questionnaire responses for 439 junior doctors. Although this study does highlight shortcomings in the provision of protected teaching time, it does not explore the potential reasons behind this.

Flett et al (2) compared the attendance rates of $285 \mathrm{SHOs}$ among three different specialties at postgraduate teaching within the same Deanery. The attendance rate was found to be as low as $40.8 \%$ with only $55.1 \%$ of responders stating they had protected teaching time. The study reported 'service commitments' were a major obstacle to attendance but the study did not include any surgical trainees and was based solely on quantitative questionnaires and therefore lacked rich, qualitative data.

Tasker et al. (3) and Anyiam et al (4) similarly identified service commitments and staff shortages as barriers to attending teaching. These difficulties may potentially be addressed however by 'Trusts that accept responsibility to educate and train their SHOs' although such 'in-house' teaching is challenging to implement $(5,6)$.

There are currently no published studies reporting upon the effectiveness of a local teaching programme at a specialist orthopaedic hospital, or indeed any other specialist hospital. Many of the SHOs within the hospital Trust at whom this teaching is aimed are not in formal training programmes. For them it therefore may represent their only regular formal teaching opportunity, placing an even greater significance upon it.

Given the importance of this teaching programme to SHOs within the Trust and the current absence of any published reports of comparable programmes, the aim of this study is to elicit SHO perspectives on the educational benefits of a local teaching programme at a specialist orthopaedic hospital. Through this process, the relevance and value of the current teaching programme can be assessed as well as identifying means by which it may potentially be improved?

\section{Methods}

Questionnaires were chosen as the method of data collection as it was felt by the authors a well-designed questionnaire compiled predominantly to extract rich qualitative data would provide the information needed to address the research questions and provide an opportunity for all SHOs within the Trust to participate within the study.

Focus groups and structured interviews were considered but deemed not appropriate for the purposes of this study predominately for pragmatic reasons. The relatively limited number of SHOs within the hospital and their busy clinical work load leads to a very pressured working environment making more time consuming methods of data collection unfeasible. 
Participants were selected by a combination of both convenience and purposive sampling. An email was sent to all the SHOs within the Trust containing an information sheet informing them of the nature of the study. A copy of the questionnaire was also attached to the email for reference.

Multiple printed copies of the questionnaire were provided to the current 'SHO lead' for the teaching programme to circulate at teaching sessions and return to the study author completed anonymously. The 'SHO lead' for the teaching programme attends virtually every teaching session, thereby giving multiple opportunities for the other $\mathrm{SHO}$ s who may attend the teaching programme more sporadically to complete the questionnaire. The option of returning the emailed questionnaire completed anonymously to the author's hospital 'pigeon hole' was also offered, thereby giving even the SHOs who may never attend teaching the opportunity to express their opinions.

Questions were included to determine duration of post-graduate experience, current career grade and career aspirations to help establish the heterogeneity of the group the teaching programme was being delivered to.

The study was conducted between January-April 2019. Formal ethics approval was not required as no randomisation or group comparison was to be performed. The surveys were anonymised.

Responses written within completed questionnaires underwent thematic analysis. A hybrid model of a priori coding based on assumed responses and emergent coding to reflect any unexpected responses was utilised.

The initial aim was to receive a response from at least $12(50 \%)$ of the SHOs within the Trust. This number was to be re-evaluated during the study period to determine if theme saturation was apparent on attainment of the provisional target of participants.

\section{Results}

Completed questionnaires were returned from a total of $12 \mathrm{SHOs}$. There was a broad spectrum of postgraduate medical experience amongst responders, ranging from 1.5-10.0 years (mean 4.1 years). Only 4 responders were in a 'Core' surgical training programme and 8 responders were 'Trust grade' service SHOs with the length of time of all responders being employed within the Trust ranging from 3 months 2 years (mean 9.8 months). In terms of frequency of attendance, 6 responders attended 'nearly always', 5 'sometimes' and 1 'rarely'. A diverse range of career aspirations were expressed amongst responders as follows; 4 orthopaedic surgeons, 3 general practitioners, 2 radiologists, 1 medical director, 1 sports \& exercise medicine physician and 1 'undecided'.

After thematic analysis of the 12 completed questionnaires, theme saturation was reached and therefore additional participants were not required.

A total of 12 codes were identified which led to the formation of 4 themes: 
1. Quality/utility of teaching

2. Content of teaching

3. Accessibility of teaching

4. Non-educational benefits of teaching programme

Table 1 provides full details of thematic analysis, coding and quotes from questionnaires upon which these codes were formulated.

Table 1: Thematic analysis and emergent coding of completed questionnaires 


\begin{tabular}{|c|c|c|}
\hline Themes & Codes & Quotes from questionnaires \\
\hline \multirow[t]{3}{*}{$\begin{array}{l}\text { Quality/Utility } \\
\text { of teaching }\end{array}$} & $\begin{array}{l}\text { Trainee } \\
\text { perspectives } \\
\text { on quality of } \\
\text { teaching }\end{array}$ & $\begin{array}{l}\text { "Mostly the quality is pretty good" } \\
\text { "Quality generally good" } \\
\text { "Up to date teaching" } \\
\text { "Up to date knowledge" } \\
\text { "Often useful" } \\
\text { "Please continue! It is the only regular formal teaching } \\
\text { we receive" }\end{array}$ \\
\hline & $\begin{array}{l}\text { Trainee } \\
\text { perspectives } \\
\text { on utility of } \\
\text { teaching }\end{array}$ & $\begin{array}{l}\text { "Relevant topics covered" } \\
\text { "Hospital policies discussed" } \\
\text { "Useful to be taught concepts which have clinical } \\
\text { applications" } \\
\text { "Difficult to comment on. Juggling ortho core trainees } \\
\text { and G.P trainees means it's difficult to gain enough } \\
\text { specific teaching matching my needs" } \\
\text { "At times is a little basic although I appreciate the } \\
\text { teaching covers a wide range of subjects" } \\
\text { "Benefits in improving knowledge" } \\
\text { "Helps improve knowledge" } \\
\text { "Gives the chance to refresh knowledge on topic you } \\
\text { don't deal with frequently" } \\
\text { "Aids learning" } \\
\text { "Yes, teaching programme relevant to my educational } \\
\text { needs" } \\
\text { "Good knowledge for common daily queries" } \\
\text { "Covers medical and surgical knowledge" } \\
\text { "The sessions I have attended did not cover } \\
\text { orthopaedic/surgical topics therefore not directly } \\
\text { relevant to my educational needs" }\end{array}$ \\
\hline & $\begin{array}{l}\text { Trainee } \\
\text { perspectives } \\
\text { on teacher } \\
\text { delivering } \\
\text { session }\end{array}$ & $\begin{array}{l}\text { "Prefer Consultant lead teaching" } \\
\text { "Benefits from teaching being delivered by senior } \\
\text { clinicians" } \\
\text { "Encourage Registrars to give more teaching sessions" }\end{array}$ \\
\hline $\begin{array}{l}\text { Content of } \\
\text { teaching }\end{array}$ & $\begin{array}{l}\text { Choice } \\
\text { topics }\end{array}$ & $\begin{array}{l}\text { "Interesting topics" } \\
\text { "Generally topics helpful" } \\
\text { "It would be useful to have more orthopaedic teaching } \\
\text { specifically" } \\
\text { "More orthopaedic subjects", }\end{array}$ \\
\hline
\end{tabular}




\begin{tabular}{|c|c|c|}
\hline & & $\begin{array}{l}\text { "The SHOs have different backgrounds/interests from } \\
\text { aspiring GP trainees to orthopaedic trainees. It is } \\
\text { therefore difficult/impossible for teachers to keep topic } \\
\text { relevant for everyone" } \\
\text { "Orthopaedic trainees would prefer Orthopaedic } \\
\text { teaching aimed at a higher level but appreciate this may } \\
\text { be difficult to arrange" }\end{array}$ \\
\hline & $\begin{array}{l}\text { Suggestions } \\
\text { for } \\
\text { enhancement }\end{array}$ & $\begin{array}{l}\text { "Topics should be interesting for most the SHOs, not } \\
\text { focused on specific areas" } \\
\text { "More radiology teaching" } \\
\text { "Include teaching on different types of implants" } \\
\text { "Continue learning in related fields like pathology and } \\
\text { haematology etc" }\end{array}$ \\
\hline & $\begin{array}{ll}\text { Methods } & \text { of } \\
\text { delivery } & \text { of } \\
\text { content } & \end{array}$ & $\begin{array}{l}\text { "More hands on training" } \\
\text { "More interactive media" } \\
\text { "More slideshows" } \\
\text { "Include videos demonstrating surgical procedures" }\end{array}$ \\
\hline $\begin{array}{l}\text { Accessibility } \\
\text { of teaching }\end{array}$ & $\begin{array}{l}\text { Clinical } \\
\text { commitments } \\
\text { preventing } \\
\text { attendance }\end{array}$ & $\begin{array}{l}\text { "Teaching falls on theatre days" } \\
\text { "Busy doing ward jobs" } \\
\text { "On-calls" } \\
\text { "Sometimes it's my clinic day and I am therefore unable } \\
\text { to attend" }\end{array}$ \\
\hline & $\begin{array}{l}\text { Physical } \\
\text { barriers to } \\
\text { attendance }\end{array}$ & $\begin{array}{l}\text { "At Bolsover Street clinic (off-site) every other week } \\
\text { during teaching" } \\
\text { "Teaching is on-site, therefore generally convenient to } \\
\text { attend" }\end{array}$ \\
\hline & $\begin{array}{l}\text { Protection of } \\
\text { teaching time }\end{array}$ & $\begin{array}{l}\text { "Is bleep protected" } \\
\text { "Good that it is bleep free" }\end{array}$ \\
\hline & $\begin{array}{l}\text { Suggestions to } \\
\text { improve } \\
\text { access }\end{array}$ & $\begin{array}{l}\text { "Attendance quite variable. Make teaching compulsory } \\
\text { as will improve attendance" } \\
\text { "Reduce frequency to once every two weeks" }\end{array}$ \\
\hline $\begin{array}{l}\text { Non- } \\
\text { educational } \\
\text { benefits of } \\
\text { teaching } \\
\text { programme }\end{array}$ & $\begin{array}{l}\text { Social benefits } \\
\text { of teaching } \\
\text { programme }\end{array}$ & $\begin{array}{l}\text { "Chance to meet other SHOs and fellow colleagues } \\
\text { you're working with" } \\
\text { "Lunch being provided is a nice gesture to the SHOs } \\
\text { there. Thank you" } \\
\text { "Food provided" } \\
\text { "Often the only chance to meet with SHOs not working } \\
\text { within my department" }\end{array}$ \\
\hline
\end{tabular}




\begin{tabular}{|l|l|} 
& "Opportunity to get to know other SHOs in the hospital" \\
\hline Peer support & $\begin{array}{l}\text { "Provides an opportunity to discuss work and training } \\
\text { related issues with colleagues" }\end{array}$ \\
\hline
\end{tabular}

\section{Discussion}

In terms of quality of the current teaching programme, the feedback was largely positive, being described as as 'generally good', 'often useful' and 'up to date'. It was clear from the responses the teaching was well received, especially by the Trust grade SHOs for whom this teaching programme represents their only formal regular teaching, epitomised by the comment 'please continue! It is the only regular formal teaching we receive'.

Not unexpectedly given the diverse range of educational needs of this heterogeneous learning group, opinions on the utility and content of the teaching programme were somewhat more varied. The majority of Trust grade SHOs felt the 'teaching programme relevant' to their educational needs and contained an appropriate content which 'helped improve knowledge', covered 'relevant topics' and found it 'useful to be taught concepts which have clinical applications'. This was not universal however and in particular the 'Core' surgical trainees and some of the more experienced Trust SHOs suggested the teaching is 'at times a little basic' and does not always cover 'orthopaedic/surgical topics' making them feel it was not always 'directly relevant to my educational needs' and would therefore prefer 'more orthopaedic subjects'.

There was an appreciation demonstrated by the more senior trainees however regarding the reasons for this, commenting on the difficulty in 'juggling ortho core trainees and general practice trainees' meaning that inevitably 'it's difficult to gain enough specific teaching matching my needs' and although 'orthopaedic trainees would prefer orthopaedic teaching aimed at a higher level', this would be 'difficult to arrange' and is 'impossible for teachers to keep the topic relevant for everyone'.

In terms of the learner perspectives on the person delivering the teaching, it was generally felt the programme 'benefits from teaching being delivered by senior clinicians' and there was a preference towards 'consultant lead teaching'. Sessions delivered by non-Consultants were also well received however, with a suggestion being made to 'encourage registrars to give more teaching sessions' and indeed the potential of near-peer teaching to enhance the training of junior doctors is widely described in medical education literature (7).

There was also a demand for more 'hands on' teaching sessions and it was expressed 'more interactive media', 'slide shows' and 'videos demonstrating surgical procedures' would be well received. This demonstrates a variety of preferred learner styles within the group, as described in Flemming's VARK model (8). 
In order to enhance the teaching programme, the general theme was compromise is required to make it relevant to all and that 'topics should be interesting for most the SHOs' and 'not focused on specific areas'. In keeping with this, suggestions were made for a greater emphasis on 'learning in related fields like pathology and haematology' and for 'more radiology teaching' to be included as part of the programme.

Barriers to attending post-graduate medical education programmes are well recognised (9-11). Workplace related barriers such as clinical commitments were the most frequently cited barriers to attendance in this study. Reasons for not being able to attend included 'teaching falls on theatre days', 'on-call', 'busy doing ward jobs' and 'sometimes it's my clinic day and I am therefore unable to attend'. There was an appreciation expressed by those who did make it to the teaching sessions however that the 'teaching is bleep protected' and it is 'good that it is bleep free'.

Physical barriers to attendance were not frequently cited to be an issue within this study as the 'teaching is on-site, therefore generally convenient to attend'. Despite this, attendance at the teaching programme has anecdotally been described as being 'quite variable' with a suggestion therefore made to 'make teaching compulsory as will improve attendance'. Although the current teaching programme is bleep protected and provided for the benefit of all SHOs within the Trust, individual attendance is not currently closely scrutinised.

The non-educational benefits of the teaching programme were identified by numerous trainees. The social benefits of what is 'often the only chance' to 'get to know other SHOs in the hospital' was cited by many as a positive aspect of the teaching programme and 'lunch being provided' was described as a 'nice gesture'. Its value in terms of peer support was also noted as it 'provides an opportunity to discuss work and training related issues with colleagues'.

Given half the SHO within the Trust completed the survey, we feel this study does provide a realistic insight into their perspectives of the current teaching programme and aspects of it they would like to enhance. There may inevitably be an element of volunteer bias affecting the outcome, as the views expressed by the trainees who took the time to complete the questionnaire may not necessarily reflect the views of those who did not complete the questionnaire. In order to minimise this bias, the option of participating in the study remotely was conveyed to all SHOs and the questionnaires were circulated at multiple teaching sessions to allow even infrequent attenders an opportunity to submit as response. Despite these measures however, it is unlikely that all bias was completed eliminated.

It is unfortunately not possible to draw a like for like comparison between this and any other study due to the absence of any other published studies which address the exact same question. It does however illustrate the teaching programme in question is generally well received and is felt to provide multiple benefits, both educational and non-educational to those that attend. It also highlights the difficulties in delivering a teaching programme to a learner group with such diverse educational needs and has demonstrated that barriers to attendance do still exist which are similar in nature to those described in previous studies. 


\section{Conclusion}

This study highlights the difficulties in delivering a teaching programme to a clinical learner group with varied educational needs within a specialist hospital setting. Despite these difficulties, we have demonstrated such a teaching programme can be of significant educational and non-educational benefit. Issues regarding making teaching equally relevant to all within a diverse clinical learner group may potentially be minimised by learner survey to identify educational topics of equivalent utility. Such topics can subsequently be incorporated into future teaching sessions.

\section{Abbreviations}

Senior House Officer (SHO): A term used in U.K hospitals referring to junior doctors who have previously completed their initial 12 months of post-medical school clinical training but remain supervised by consultants and registrars and are yet to commence senior 'higher' specialist training. It may encompass 'core' trainees, early years general practice trainees, Foundation year 2 doctors and non-training Trust grade doctors on junior rotas.

\section{Declarations}

Ethics approval and consent to participate:

Formal ethics approval was not required as no randomisation or group comparison was performed. Surveys were anonymised and avoided asking personal information. The University College London research ethics committee (institution where study performed) states such 'service evaluation' studies are exempt from requiring formal ethics approval:

https://ethics.grad.ucl.ac.uk/exemptions.php

Written consent was obtained from study participants.

Consent for publication:

Not applicable

Availability of data and materials:

The data supporting the results reported in the article can be found in Table 1.

Competing interests:

The authors declare they have no competing interests

Funding: 
The study received no funding

Authors' contributions:

SK collected, analysed and interpreted the data and was lead author of the manuscript. DE was the senior author and revised sections of the manuscript. All authors read and approved the final manuscript.

Acknowledgements:

Not applicable

\section{References}

1. COPMED. Committe of Postgraduate Medical Deans. SHO Training. Tackling the issues, raising the standards. 1995.

2. Flett A, Baker M, Williams J. Formal education programmes for senior house officers: comparison of experience in three hospital specialties. Postgraduate medical journal. 2001;77(912):650-3.

3. Tasker F, Dacombe P, Goddard AF, Burr B. Improving core medical training-innovative and feasible ideas to better training. Clin Med. 2014;14(6):612-7.

4. Anyiam O, Mercer $\mathrm{C}$, Zaheen $\mathrm{H}$. Participation in teaching opportunities during core medical training: barriers and enablers. Future Hospital Journal. 2017;4(2):86-91.

5. The future of. the $\mathrm{SHO}$ grade: report of the junior doctors committee working party on $\mathrm{SHO}$ training [press release]. London, BMA1998.

6. Bellman L. A qualitative evaluation of senior house officers' teaching and learning: towards sharing good practice. Med Teach. 2004;26(4):313-20.

7. Anyiam 0 , Ware V, McKenna M, Hanley J. Junior doctor teaching delivered by near peers. Clin Teach. 2018;15(5):398-402.

8. Fleming ND, Mills C. Not another inventory, rather a catalyst for reflection. To improve the academy. 1992;11(1):137-55.

9. Higgins R, Cavendish S, Gregory R. Class half-empty? Pre-registration house officer attendance at weekly teaching sessions: implications for delivering the new Foundation Programme curriculum. Medical education. 2006;40(9):877-83.

10. Carr S. Education of senior house officers: current challenges. Postgraduate medical journal. 2003;79(937):622-6.

11. Cooke L, Hurlock S. Education and training in the senior house officer grade: results from a cohort study of United Kingdom medical graduates. Medical education. 1999;33(6):418-23. 